\title{
Monozygotic twins discordant for exstrophy of the urinary bladder
}

\author{
MERETE BUGGE \\ From the Department of Urology A and University Institute of Clinical Genetics, Odense University \\ Hospital, DK-5000 Odense C, Denmark
}

SUMMARY A pair of monozygotic male twins discordant for ectopia vesicae urinariae is described. There is no reason to think that any exogenic factors contributed to the aetiology. There was no consanguinity and no history of congenital anomalies on either side of the family. Published reports concerning family incidence and twin reports are reviewed.

Exstrophy of the urinary bladder or ectopia vesicae urinariae is a severe but rare congenital malformation. The incidence is reported to be from 1 in 30000 to 1 in 50000 births. $^{1-3}$ It occurs more frequently in males than in females. The reported sex ratio varies from $2 / 1$ to $4 / 1 .^{2-4}$ The condition occurs in two forms: incomplete and complete. In the incomplete form a small opening corresponding to the anterior wall of the bladder is found. The complete form includes total exstrophy as well as epispadias or bifid clitoris, diastasis musculi recti abdominis, and diastasis rami superioris ossium pubis. The latter form is more frequent. Ectopia vesicae may be found with congenital malformations in almost any organic system forming complex malformation syndromes. The condition has been described in patients with Down syndrome, ${ }^{45}$ but only in a few cases. Extensive accounts of malformations in Down syndrome do not mention ectopia vesicae ${ }^{6}{ }^{7}$ and no connection with other known chromosome anomalies has been found. The aetiology of the cases not associated with a syndrome is unknown. Nothing certain is known of the relative influence of genetic factors.

This account describes a pair of male twins who had a $99 \%$ probability of being monozygotic. One had complete ectopia vesicae and the other had no congenital malformations.

\section{Case report}

This was the first pregnancy of a 21-year-old woman. For about one year the patient had used Mini-P (norethisterone) as a contraceptive. This was first discontinued when pregnancy was ascertained 5 weeks after the last normal menstruation. In the first 5 weeks of pregnancy the patient had taken Duspatalin tablets (Mebeverini chloridum), at the most three tablets in all. In the first two months of pregnancy she had an almost constant brown discharge per vaginam and twice had minor spottings. At approximately the eighth week of pregnancy the patient was admitted to a department of gynaecology for imminent abortion after heavy unprovoked fresh vaginal bleeding. The condition subsided after a period of rest in bed, and the pregnancy continued without complications. The mother was in good health during the entire pregnancy and in particular did not suffer from any febrile disease. She was at no time exposed to known toxic agents at her place of work. Abdominal $x$-ray at 33 weeks' gestation confirmed a suspected twin pregnancy. $X$-ray examination was not performed earlier in the pregnancy, and at no point was ultrasound examination carried out. Spontaneous and uncomplicated delivery occurred in the 38th week of gestation in an obstetric department. Both twins were delivered by the vertex.

\section{TWIN A}

This was a live boy, birthweight $2850 \mathrm{~g}$. Immediately after birth it was observed that the infant had complete ectopia vesicae. Intravenous urography showed an otherwise normal urinary system and there were no other notable malformations. Surgery was carried out, and by the age of 3 years the child was normally developed for his age, height $94.5 \mathrm{~cm}$, weight $13 \cdot 5 \mathrm{~kg}$.

\section{TWIN B}

This was a live boy, birthweight $3250 \mathrm{~g}$. No sign of 
congenital malformation was found in this infant. The child was normally developed at the age of 3 years and had never suffered from any serious illness. His height was $97.5 \mathrm{~cm}$, and weight was $14.5 \mathrm{~kg}$. $X$-ray examination of the urinary tract was not considered to be justified as the boy had no symptoms.

The parents were in the same age group and both were healthy and unrelated. On examination of the family history no evidence was found of this or other congenital malformations in any of the close relatives.

At birth the placenta was examined by an experienced obstetrician, who found a fused placenta with monochorionic, biamniotic membranes. At the age of 3 years the children looked almost completely alike. They have the same colour eyes and hair. Blood group determinations, carried out when the children were aged 2 years, showed total identity in 18 serological systems. The systems examined included the $\mathrm{A}_{1} \mathrm{~A}_{2} \mathrm{BO}, \mathrm{MNSs}, \mathrm{Rh}$ (5 antisera), $\mathrm{P}$, Kell and Duffy(a) blood groups, the $\mathrm{Hp}, \mathrm{Gc}, \mathrm{Gm}$ $(a, x, b)$ and Inv serum protein groups, and the PGM AcP, GPT, EsD, GLO, AK, PGD, and ADA enzyme polymorphisms (The Institute of Forensic Medicine, The University of Copenhagen).

These findings, with a probability of more than $99 \%$, justify the diagnosis of monozygosity.

\section{Discussion}

In the first weeks of pregnancy the mother ingested Duspatalin (Mebeverini chloridum). There are no published reports of congenital malformations occurring in children of mothers who ingested this medication during pregnancy. ${ }^{8}$ The mother continued her peroral contraceptive up to 5 weeks after her last normal menstruation. Congenital malformations associated with the urogenital system resulting from the ingestion of norethisterone during pregnancy have been described, but even the more extensive accounts do not mention ectopia vesicae. ${ }^{89}$

Familial cases of ectopia vesicae are described in published reports, but the descriptions are few and incomplete. In his work in 1958 Higgens $^{2}$ reports having treated 147 children with the condition. He mentions briefly having seen the malformation occur twice in "members of the same family". Further details, however, are not given. In 1928 Kohler ${ }^{10}$ described a boy whose male cousin had the same malformation. Four publications report bladder exstrophy in two or more sibs. Glaser and Lewis $^{3}$ described a healthy woman whose first and second child, both boys, born within a 2-year period, had ectopia vesicae. He mentions that there was no known familial predisposition to this or other congenital malformations. Chrisholm ${ }^{11}$ briefly mentions having treated a boy whose sister had the same $\stackrel{\overparen{\oplus}}{:}$ complaint. Schilling ${ }^{12}$ describes a similar case just as briefly. Randall and Harwick ${ }^{13}$ treated a girl surgically for ectopia vesicae and mentioned that her two brothers had the same malformation. She herself gave birth to a healthy child, and there are no accounts of patients with ectopia vesicae giving birth to children with the same condition. A number of of authors emphasise that they have never experienced such instances.

Four pairs of twins with ectopia vesicae are described in published reports. One discordant pair was of different sex and therefore certainly dizygotic. ${ }^{14}$ The twins in the three other pairs were of the same sex and included two pairs of boys, who were concordant, and one pair of girls who were discordant. One of the male pairs were described in 1943 by Higgins ${ }^{1}$ as "identical", but no mention was made of the reasons for this diagnosis. Only one placenta was found. He also mentioned that no similar cases were found in the family. Smith and Lattimar $^{15}$ described the other pair of boys. These were also called "identical", but no further information was given. Coates ${ }^{16}$ described the only pair of girls. The description did not include any mention of observations made for the purpose of establishing the zygosity of the twins. Thus, none of these reports contains definite information about the diagnosis of zygosity and no definite conclusion can be reached regarding possible genetic aetiology from the information given.

The present case in which ectopia vesicae occurred discordantly in a monozygotic twin pair allows the conclusion that the condition is at least not purely genetically determined. The present report does not allow for any conclusions regarding the aetiology. The limited information available suggests that an increased recurrence risk, albeit low, among sibs of affected subjects may exist. It seems, however, 3 desirable to have some estimate of this risk before recommending fetoscopy to women who have had one child with exstrophy of the urinary bladder. As far as the author is aware there is no mention in published reports of the malformation not associated $\sigma$ with a syndrone diagnosed prenatally by ultrasound $N$ examination or amniocentesis.

\section{References}

1 Higgens CC. Exstrophy of the bladder in twins. Cleve Clin $Q 1943 ; 10: 138-41$.

2 Higgens CC. An evaluation of cystectomy: for exstrophy, for papillomatosis, and for carcinoma of the bladder. J Urol 1958;80:279-92.

3 Glaser LH, Lewis APR. A case of familial incidence of ectopia vesicae. Br Med J 1961 ;ii:1333.

4 Uson AC, Lattimar JK, Melicow MM. Types of exstrophy of urinary bladder and concomitant malformations. Pediatrics 1959;23:927-34. 
5 Clark M, O'Connell K. Scanning and transmission electron microscopic studies of an exstrophic human bladder. J Urol 1973;110:481-3.

6 Øster J. Mongolism. Copenhagen: Danish Science Press, 1953.

7 Bergsma D. Birth defects. Atlas and compendium. Baltimore: Williams and Wilkins, 1977.

8 Heinonem OP, Slone D, Shapiro S. Birth defects and drugs in pregnancy. Littleton, Massachusetts: Publishing Sciences Group, 1977.

9 Nora $\mathrm{JJ}$, Nora $\mathrm{AH}$, Blu J, et al. Exogeneous progesteron and estrogen implicated in birth defects. $J A M A 1978 ; 240$ : 837-43.

10 Köhler H. Die Ureafunktionsprüfung, kontrolliert an einem Fall von totaler Blasenektopie. Zentralbl Chir 1928;23:1412-7.

11 Chrisholm TC. Exstrophy of the urinary bladder. Am J Surg $1961 ; 101: 649-55$.
12 Schilling H. Om Makka's operation ved ectopia vesicae. Förhandlingarna vid Nordisk Kirurgisk Förenings 12' möte i Kristiania 1919:130-5.

13 Randall LM, Harwick RS. Pregnancy and parturition following bilateral ureteral transplantation for congenital exstrophy of the bladder. Surg Gynecol Obstet 1934;58: 1018-22.

14 Marshall VF, Muecke EC. Variations in exstrophy of the bladder. J Urol 1962;88:766-96.

15 Smith MJV, Lattimar JK. The management of bladder exstrophy. Surg Gynecol Obstet 1966;123:1015-8.

16 Coates WH. Case of a remarkable conformation of the urinary and genital organs in a female child. Edinburgh Med Surg $J$ 1805;1:39-42.

Requests for reprints to Dr M Bugge, Department of Urology A, Odense University Hospital, DK-5000 Odense C, Denmark. 